ARTICLE

https://doi.org/10.1038/s41467-019-09495-1

\title{
Temperature-controlled repeatable scrambling and induced-sorting of building blocks between cubic assemblies
}

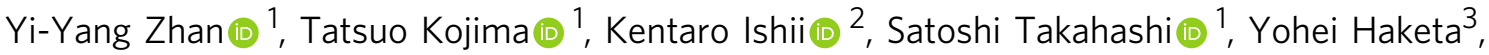 \\ Hiromitsu Maeda (10 ${ }^{3}$, Susumu Uchiyama (i) ${ }^{2,4} \&$ Shuichi Hiraoka (i) ${ }^{1}$
}

Separation of a homogeneous mixture of different components to reach an ordered out-ofequilibrium state in solution has attracted continuous attention. While this can be achieved using external chemical fuels or photo energy, an alternative energy source is heat. Here we realize a temperature-controlled cycle of transitions between ordered and disordered states based on a mixture of two kinds of building blocks that self-assemble into cubic structures (nanocubes). An almost statistical mixture of nanocubes (disordered state) is thermodynamically most stable at lower temperature $\left(25^{\circ} \mathrm{C}\right.$ ), while homoleptic assemblies composed of single components are preferentially produced at higher temperature $\left(100^{\circ} \mathrm{C}\right)$ followed by rapid cooling. The scrambling of the building blocks between the nanocubes takes place through the exchange of free building blocks dissociated from the nanocubes. Based on this mechanism, it is possible to accelerate, retard, and perfectly block the scrambling by the guest molecules encapsulated in the nanocubes.

\footnotetext{
${ }^{1}$ Department of Basic Science, Graduate School of Arts and Sciences, The University of Tokyo, 3-8-1 Komaba, Meguro-ku, Tokyo 153-8902, Japan. 2 Exploratory Research Center on Life and Living Systems (ExCELLS), National Institutes of Natural Sciences, 5-1 Higashiyama, Myodaiji-cho, Okazaki, Aichi 444-8787, Japan. ${ }^{3}$ Department of Applied Chemistry, College of Life Sciences, Ritsumeikan University, 1-1-1 Noji-higashi, Kusatsu, Shiga 525-8577, Japan. ${ }^{4}$ Department of Biotechnology, Graduate School of Engineering, Osaka University, 2-1 Yamadaoka, Suita, Osaka 565-0871, Japan. Correspondence and requests for materials should be addressed to S.H. (email: chiraoka@mail.ecc.u-tokyo.ac.jp)
} 
T wo kinds of different gases put into a box spontaneously mix together to reach a homogeneous fluid in equilibrium. Such a disordered state is thermodynamically favored and entropy is the quantity that determines which direction a reaction spontaneously proceeds to. Thus, the separation of each component from a homogeneous mixture (towards ordered state) needs external energy or help of Maxwell's demon if we want to realize the separation without any energy except for information ${ }^{1-4}$. The homogeneity of a mixture of gases in equilibrium derives from their negligibly weak interactions. Contrary to mixing of gases, molecular self-assembly of multiple components can spontaneously form homoleptic self-assemblies composed of single components through self-sorting under thermodynamic control with the aid of intermolecular interactions between well-designed molecular building blocks that discriminate between oneself and others ${ }^{5-19}$. Furthermore, in the case where a statistical mixture of components in molecular assemblies is thermodynamically preferred, recent progress on adaptive chemistry has realized the transition of such disordered states into an ordered out-of-equilibrium state by external photo or chemical energy ${ }^{20-34}$.

Here we present a simple example of a temperature-controlled reversible transition between ordered and disordered states consisting of a mixture of two kinds of molecular building blocks that self-assemble into hexameric cubic structures, i.e. nanocubes, with different thermal stabilities. Because of a structural similarity between the two components (A and B for example), scrambling of the building blocks between the nanocubes $\left(\mathrm{A}_{6}\right.$ and $\left.\mathrm{B}_{6}\right)$ spontaneously takes place at $25^{\circ} \mathrm{C}$ to reach an almost statistical mixture of nanocubes composed of two kinds of building blocks, $\mathrm{A}_{n} \mathrm{~B}_{6-n}(n=0-6)$, a disordered state. Then, a metastable ordered state (a mixture of homoleptic nanocubes composed of a single component, $\mathrm{A}_{6}$ and $\mathrm{B}_{6}$ ) is spontaneously recovered by heating at $100^{\circ} \mathrm{C}$ and subsequent rapid cooling. The reversible transition between the two states is realized by the change in the energy landscape of the system consisting of two kinds of building blocks in response to the temperature. It is also found that the scrambling is accelerated, retarded, or blocked by guest molecules encapsulated in the nanocubes, which enables us to lock and unlock a metastable state by the encapsulation and release of hydrophobic molecules in the nanocubes.

\section{Results}

Scrambling between nanocubes. Gear-shaped amphiphiles (GSA: $\mathbf{1} \cdot \mathrm{Cl}_{2}$ and $\mathbf{2} \cdot \mathrm{Cl}_{2}$ ), which are $C_{2 \mathrm{v}}$-symmetric hexaphenylbenzene (HPB) derivatives possessing three kinds of substituents on the periphery of HPB, self-assemble into a cubeshaped structure (nanocubes, $\mathbf{1}_{6}$ and $\mathbf{2}_{6}$ ) in water driven by the hydrophobic effect and van der Waals (vdW) and cation $-\pi$ interactions between GSA molecules (Fig. 1a) ${ }^{35-37}$. Though the structures of $\mathbf{1}$ and $\mathbf{2}$ are very similar, $\mathbf{1}_{6}$ is thermally more stable than $\mathbf{2}_{6}$ because vdW interactions around $p$-tolyl methyl groups of $\mathbf{1}_{6}$ significantly enhance its thermal stability (disassembly temperature $\left(T_{\mathrm{d}}\right)$ of $\mathbf{1}_{6}$ is $130^{\circ} \mathrm{C}$, while that of $\mathbf{2}_{6}$ is $\left.65^{\circ} \mathrm{C}\right)$. To investigate the relation between the thermal and kinetic stabilities of the nanocubes, scrambling of GSAs between nanocubes assembled from non-deuterated GSAs $\left(\mathbf{1}_{6}\right.$ or $\mathbf{2}_{6}$ ) and from partially deuterated GSAs $\left((\mathbf{1 D})_{6}\right.$ or $\left.(\mathbf{2 D})_{6}\right)$ was monitored by electrospray ionization-time-of flight (ESI-TOF) mass spectrometry. When aqueous solutions of $\mathbf{1}_{6}$ and $(\mathbf{1 D})_{6}$ were mixed at room temperature $([\mathbf{1}]=[\mathbf{1 D}]=0.025 \mathrm{mM})$, the scrambling was clearly monitored by change in the distribution of mass signals for $\left[\mathbf{1}_{x}(\mathbf{1 D})_{6-x}\left(\mathrm{SO}_{4}\right)_{6}\right]^{2-}(x=0-6)$, which captured two electrons during the ionization (an aqueous $\mathrm{H}_{2} \mathrm{SO}_{4}$ solution was added just before the mass measurement in order to detect the nanocubes as negative ion species), and an almost statistical signal pattern was observed in 2 days (Fig. 2a). In contrast, the scrambling for a mixture of thermally less stable nanocubes, $\mathbf{2}_{6}$ and $(\mathbf{2 D})_{6}$, finished just after the mixing of the two solutions (Fig. 2b), indicating that the rate of the scrambling is related to the thermal stability of the nanocubes. It was also found that the rate of the scrambling is dependent on the concentration; the scrambling took place faster at lower concentration of the nanocubes (Fig. 2a). This result indicates that the scrambling does not occur by the collision of the nanocubes but through the exchange of monomer GSAs dissociated from the nanocubes (Fig. 2d) even though the signals for free GSAs were not observed by ${ }^{1} \mathrm{H}$ NMR spectroscopy.

Next, the scrambling between the two different nanocubes $\left(\mathbf{1}_{6}\right.$ and $\mathbf{2}_{6}$ ) was monitored by ESI-TOF mass spectrometry (Fig. 2c). When $\mathbf{1}_{6}$ and $\mathbf{2}_{6}([\mathbf{1}]=[2]=0.4 \mathrm{mM})$ were mixed at $25^{\circ} \mathrm{C}$, the signal for $\mathbf{2}_{6}$ decreased faster than that for $\mathbf{1}_{6}$ and finally reached an almost statistical compositional mixture of the nanocubes in 2 days. The scrambling in the same concentration of the nanocubes $([\mathbf{1}]=[\mathbf{2}]=0.4 \mathrm{mM})$ was monitored by ${ }^{1} \mathrm{H}$ NMR spectroscopy (Fig. 3a and Supplementary Fig. 3). The ${ }^{1} \mathrm{H}$ NMR spectra of a 1:1 mixture of $\mathbf{1}_{6}$ and $\mathbf{2}_{6}$ at $25^{\circ} \mathrm{C}$ changed for 2 days, which is consistent with the time taken for the convergence of mass signals of a mixture of $\mathbf{1}_{6}$ and $\mathbf{2}_{6}$. As observed by the mass measurements, the ${ }^{1} \mathrm{H}$ NMR signals for $\mathbf{2}_{6}$ decreased faster than those for $\mathbf{1}_{6}$, indicating that the heteroleptic nanocubes, $\mathbf{1}_{x} \mathbf{2}_{6-x}(x=1-5)$, tend to preferentially exchange GSAs with $\mathbf{2}_{6}$ because the scrambling between less stable nanocubes takes place faster, which supports the idea that the scrambling takes place through the exchange of monomer GSAs dissociated from the nanocubes. The scrambling was accelerated by heating and reached convergence in $8 \mathrm{~h}$ at $50^{\circ} \mathrm{C}$.

Interconversion between ordered and disordered states. Considering the fact that $\mathbf{1}_{6}\left(T_{\mathrm{d}}=130^{\circ} \mathrm{C}\right)$ is thermally more stable than $2_{6}\left(T_{\mathrm{d}}=65^{\circ} \mathrm{C}\right)$ due to the vdW interactions around $p$-tolyl methyl groups in $\mathbf{1}$, nanocubes composed of more $\mathbf{2}$ would be less stable than those composed of more $\mathbf{1}$. Hence, at higher temperature than $T_{\mathrm{d}}$ of $\mathbf{2}_{6}$, the nanocubes composed of more $\mathbf{2}$ should be disassembled to lead to a mixture of monomer 2 and the nanocubes composed of more 1 . Then rapid cooling of the mixture of the nanocubes (mainly $\mathbf{1}_{6}$ ) and free $\mathbf{2}$ thus obtained leads to a mixture mainly containing homoleptic nanocubes $\left(\mathbf{1}_{6}\right.$ and $\mathbf{2}_{6}$ ) through faster self-assembly of monomer $\mathbf{2}$ into $\mathbf{2}_{6}$ than the scrambling (Fig. 1b, c). As expected, heating of a mixture of $\mathbf{1}_{6}$ and $2_{6}$ at $100{ }^{\circ} \mathrm{C}$ led to the homoleptic $\mathbf{1}_{6}$ in $83 \%$ yield (Fig. $3 \mathrm{c}$ and Supplementary Fig. 5). Subsequent rapid cooling at $0{ }^{\circ} \mathrm{C}$ gave homoleptic nanocubes (ordered state) in $70.7 \pm 0.7 \%$ yield (Fig. $3 \mathrm{c}$ and Supplementary Fig. 6). At $50{ }^{\circ} \mathrm{C}$, this mixture was gradually converted into an almost statistical mixture of nanocubes $\mathbf{1}_{x} \mathbf{2}_{6-x}$ $(x=0-6)$ (disordered state), which is thermodynamically most stable at $50^{\circ} \mathrm{C}$. The interconversion between the ordered and disordered states is repeatable simply by changing the temperature of the solution without any degradation because the GSAs are completely stable even at $100^{\circ} \mathrm{C}$ (Fig. 3b).

Guest effect on scrambling. As the nanocubes can encapsulate neutral and anionic species in their about-1-nm-sized hydrophobic inner space to lead to thermally more stable nanocubes ${ }^{37}$, the guest species would prevent the dissociation of the nanocubes into the monomers, thereby retarding the scrambling. When aqueous solutions of $\mathbf{1}_{6}$ encapsulating two molecules of 1,3,5tribromomesitylenes (TBM), TBM ${ }_{2} @ \mathbf{1}_{6}\left(T_{\mathrm{d}}>150^{\circ} \mathrm{C}\right)$, and of $\mathbf{2}_{6}$ $\left(T_{\mathrm{d}}=65^{\circ} \mathrm{C}\right)$ were mixed, nothing happened for 6 months (Supplementary Fig. 7); the scrambling of GSAs and the distribution of TBM molecules between the nanocubes were perfectly blocked 
a

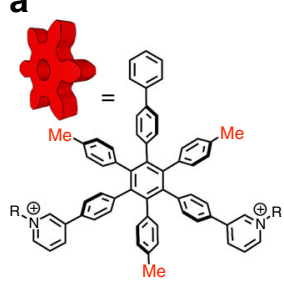

1: $\mathrm{R}=\mathrm{CH}_{3}$ 1D: $\mathrm{R}=\mathrm{CD}_{3}$

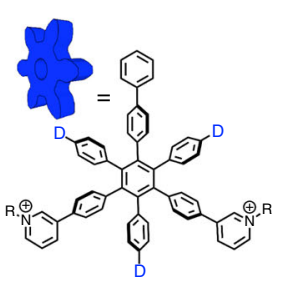

2: $\mathrm{R}=\mathrm{CH}_{3}$

2D: $\mathrm{R}=\mathrm{CD}_{3}$ b

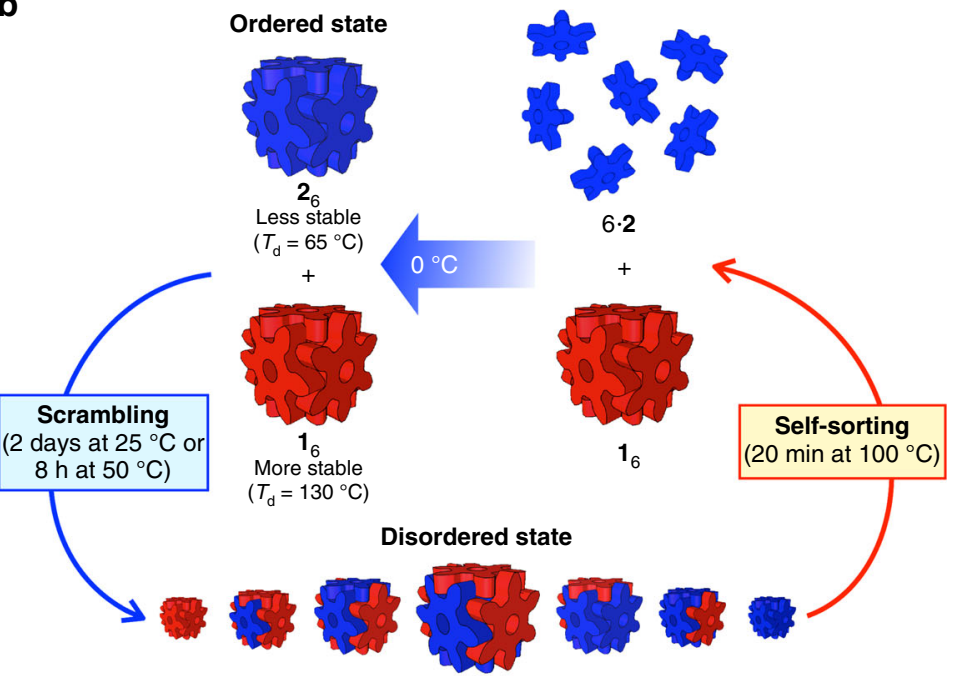

An almost statistical mixture of $\mathbf{1}_{x} \mathbf{2}_{6-x}(x=0-6)$

C

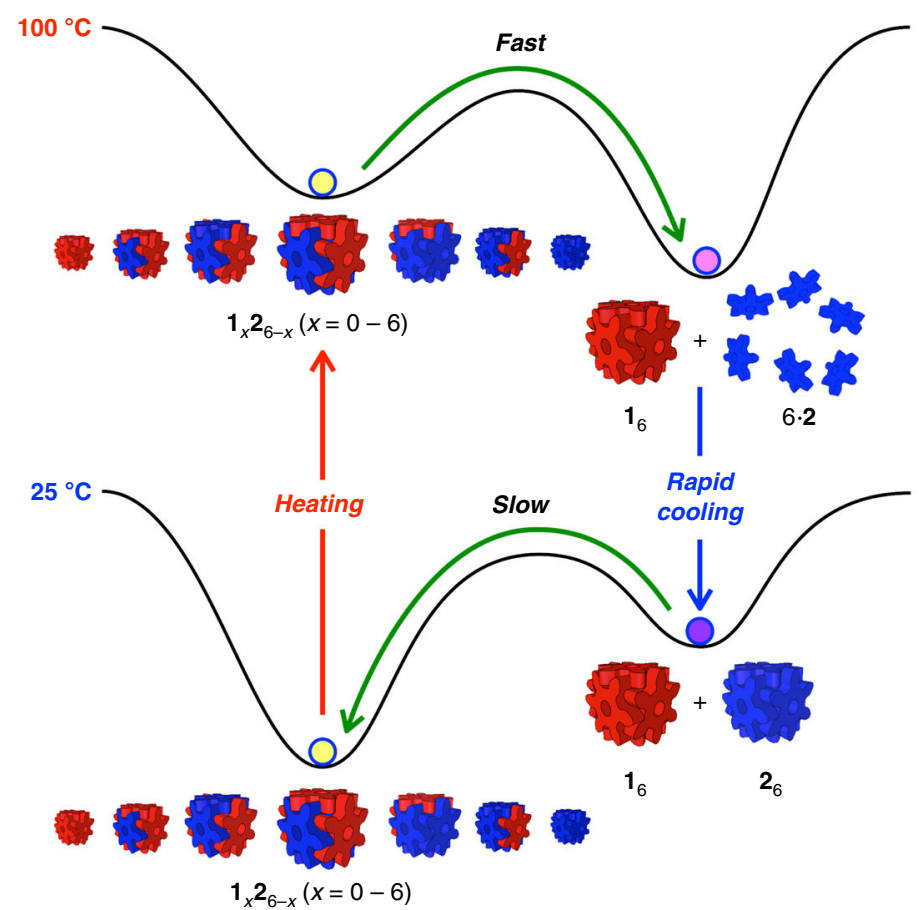

Fig. 1 A temperature-controlled cycle of transitions between ordered and disordered states in a mixture of nanocubes $\left(\mathbf{1}_{6}\right.$ and $\left.\mathbf{2}_{6}\right)$. a The chemical structures of GSAs used in this research. $\mathbf{b}$ A temperature-controlled cycle of the conversion between the ordered and disordered states. An almost statistical mixture of the nanocubes (disordered state) was produced at 25 or $50^{\circ} \mathrm{C}$, while a mixture of two kinds of nanocubes composed of single GSAs was preferentially produced by heating at $100{ }^{\circ} \mathrm{C}$ followed by rapid cooling at $0{ }^{\circ} \mathrm{C}$. There are positional isomers for $\mathbf{1}_{x} \mathbf{2}_{6-x}(x=2-4)$. c $\mathrm{A}$ schematic representation of change in the energy landscape of a mixture of two kinds of GSAs, $\mathbf{1}$ and $\mathbf{2}$, in response to the temperature. An almost statistical mixture of nanocubes $\mathbf{1}_{x} \mathbf{2}_{6-x}(x=0-6)$ is thermodynamically most stable at $25^{\circ} \mathrm{C}$, while a mixture of $\mathbf{1}_{6}$ and monomer $\mathbf{2}$ is thermodynamically most stable at $100{ }^{\circ} \mathrm{C}$ because decomposition temperatures of the nanocubes composed of more GSAs $\mathbf{2}$ are lower than $100^{\circ} \mathrm{C}$

(Fig. 4a). The same result was found when aqueous solutions of $\mathrm{TBM}_{2} @ \mathbf{2}_{6}\left(T_{\mathrm{d}}=135^{\circ} \mathrm{C}\right)$ and $\mathbf{1}_{6}\left(T_{\mathrm{d}}=130^{\circ} \mathrm{C}\right)$ were mixed (Supplementary Fig. 8). These results indicate that the encapsulated hydrophobic guest molecules stabilize the nanocubes to change the energy landscape, resulting in the suppression of the dissociation of free GSAs (Fig. 4d). Interestingly, when insoluble TBM existed in an aqueous solution of $\mathrm{TBM}_{2} @ 2_{6}$ and $\mathbf{1}_{6}$, the scrambling took place slowly. (It took 26 days to reach equilibration, which is longer than the time for the scrambling between $\mathbf{1}_{6}$ and $\mathbf{2}_{6}, 2$ days.) (Supplementary Fig. 9). Insoluble TBM molecules were gradually encapsulated in $\mathbf{1}_{6}$, during which the structure of the $\mathbf{1}_{6}$ nanocube would partially be broken or free GSAs would be dissociated. Hence, these (partially) dissociated GSAs of 1 should promote the scrambling. On the other hand, no scrambling took place when insoluble TBM was present in a solution of $\mathrm{TBM}_{2} @ \mathbf{1}_{6}$ and $\mathbf{2}_{6}$, though gradual encapsulation of TBM in $\mathbf{2}_{6}$ was observed (Supplementary Fig. 10). In this case, though the encapsulation of TBM into $\mathbf{2}_{6}$ caused the dissociation of monomer GSA 2, the dissociation of monomer GSA 1 was strongly prevented by the encapsulation of TBM into $\mathbf{1}_{6}\left(T_{\mathrm{d}}>150^{\circ} \mathrm{C}\right)$, so the scrambling did not take place. 
a

$$
\bullet:\left[\mathbf{1}_{6}+6 \cdot \mathrm{SO}_{4}\right]^{2-} \quad \bullet:\left[(1 \mathrm{D})_{6}+6 \cdot \mathrm{SO}_{4}\right]^{2-}
$$
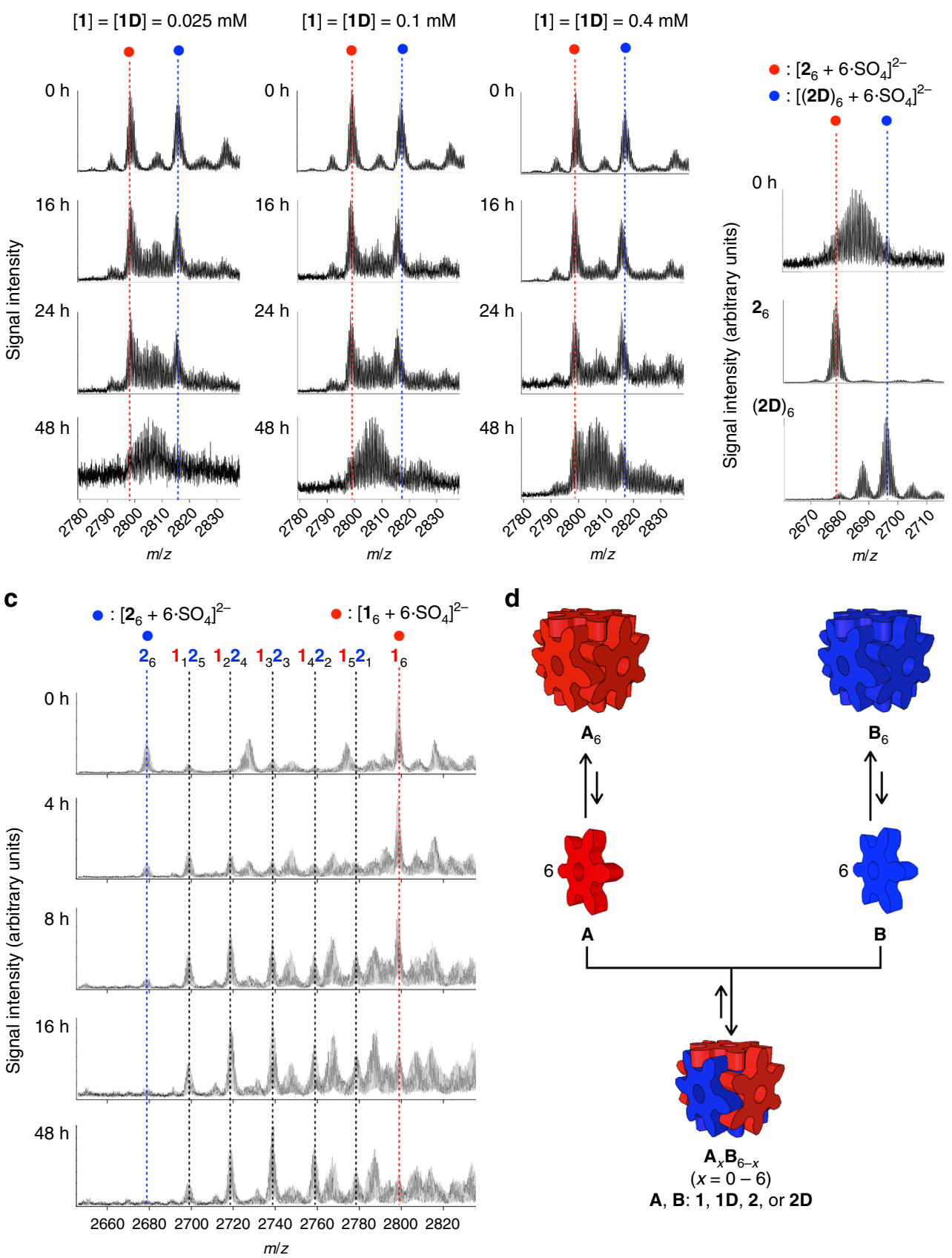

$A, B: 1,1 D, 2$, or $2 D$

Fig. 2 Monitoring of scrambling of GSAs between the nanocubes by ESI-TOF mass spectrometry and scrambling mechanism. a The scrambling of GSAs between $\mathbf{1}_{6}$ and (1D) 6 was monitored in different concentrations. Right after the mixing of aqueous solutions of $\mathbf{1}_{6}$ and (1D) ${ }_{6}$, strong signals for the homoleptic nanocubes (indicated by solid blue and red circles) were observed. These signals became weak with time and new signals assigned to heteroleptic nanocubes appeared in between the two signals. The scrambling takes place faster in lower concentration of the nanocubes. $\mathbf{b}$ The scrambling of GSAs between $\mathbf{2}_{6}$ and (2D) ${ }_{6}$. The scrambling was completed right after the mixing of $\mathbf{2}_{6}$ and (2D) ${ }_{6}$, which is much faster than the scrambling between $\mathbf{1}_{6}$ and (1D) $)_{6}$. c The scrambling of GSAs between $\mathbf{1}_{6}$ and $\mathbf{2}_{6}$ was monitored after mixing of aqueous solutions of $\mathbf{1}_{6}$ and $\mathbf{2}_{6}$. The conversion of the less stable nanocube ( $\left.\mathbf{2}_{6}\right)$ into heteroleptic nanocubes, $\mathbf{1}_{x} \mathbf{2}_{6-x}(x=1-5)$, is faster than that of $\mathbf{1}_{6}$. $\mathbf{d}$ The scrambling of GSAs between the nanocubes $\mathbf{A}_{6}$ and $\mathbf{B}_{6}$ takes place through the exchange of monomer GSAs dissociated from the nanocubes. After the formation of heteroleptic nanocubes $\mathbf{A}_{x} \mathbf{B}_{6-x}(x=1-5)$, the scrambling of $\mathbf{A}_{x} \mathbf{B}_{6-x}(x=1-5)$ with the less stable homoleptic nanocube takes place faster than with the more stable one

These results indicate that whether the scrambling takes place or not is determined by the existence of monomer GSAs ( 1 and 2 ) and that in the case where the thermal stabilities of the two nanocubes are significantly different the rate-determining step of the scrambling is the dissociation of monomer GSAs from a thermally more stable nanocube.
Quite different results were observed when anionic species (NaPCCP: sodium pentacyanocyclopentadienide) was used as a guest molecule (Fig. 4b). When PCCP @ $_{6}$ and $\mathbf{2}_{6}$ were mixed together, the scrambling was significantly retarded $(65 \%$ of PCCP $2_{2} \mathbf{1}_{6}$ and $20 \%$ of $\mathbf{2}_{6}$ existed in the solution after 1 month) (Supplementary Fig. 11). Furthermore, the scrambling was 
a

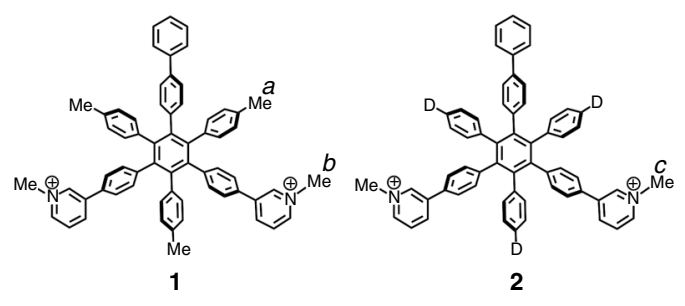
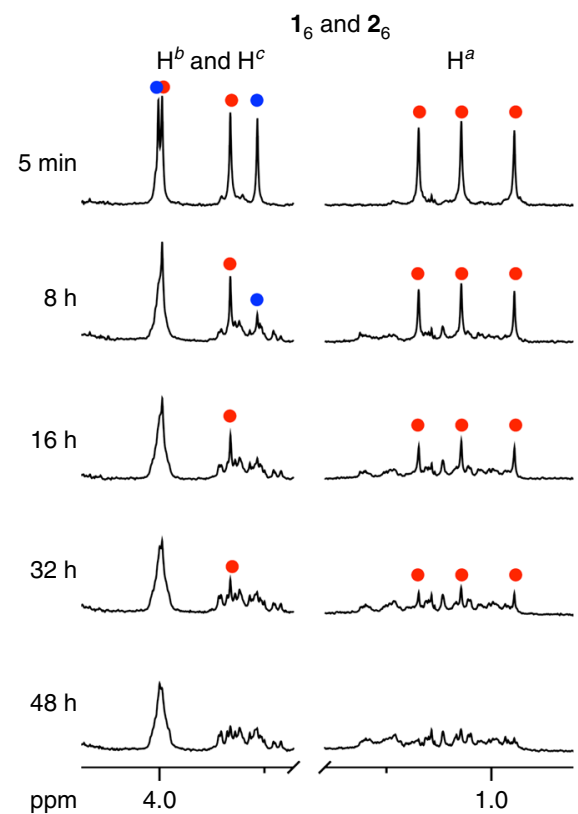

b

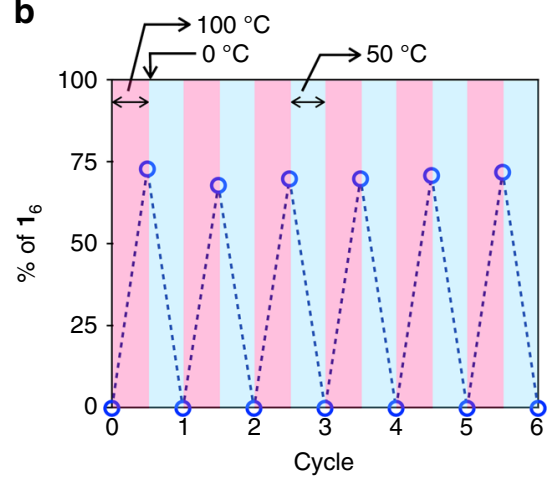

C

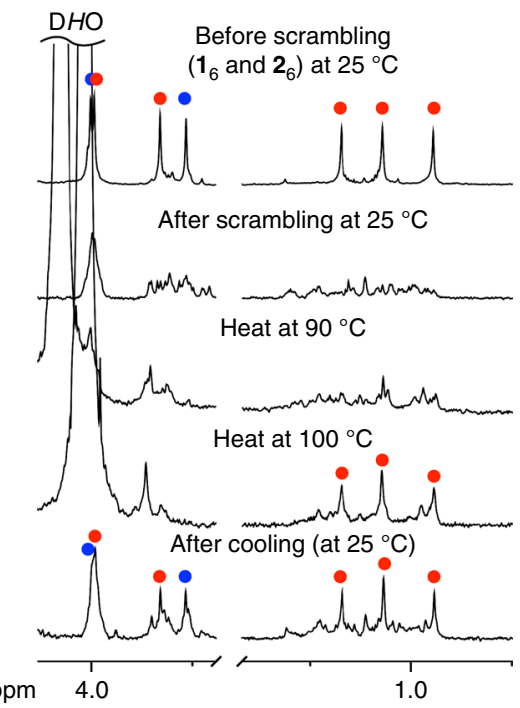

Fig. 3 Scrambling and induced-sorting of GSAs between the nanocubes $\left(\mathbf{1}_{6}\right.$ and $\left.\mathbf{2}_{6}\right)$. The scrambling and induced-sorting were monitored by ${ }^{1} \mathrm{H}$ NMR spectroscopy ( $500 \mathrm{MHz}, \mathrm{D}_{2} \mathrm{O}, p$-tolyl methyl and $\mathrm{N}$-methyl group regions, [1] $=[\mathbf{2}]=0.4 \mathrm{mM}$ ). a The monitoring of the scrambling of GSAs between $\mathbf{1}_{6}$ and $\mathbf{2}_{6}$ at $298 \mathrm{~K}$. Red and blue solid circles indicate the signals for $\mathbf{1}_{6}$ and $\mathbf{2}_{6}$, respectively. $\mathbf{b}$ A plot of the existence ratio of $\mathbf{1}_{6}$ in a 1:1 mixture of $\mathbf{1}$ and $\mathbf{2}$ during six cycles of the transitions between the ordered and disordered states by changing temperature. $\mathbf{c}{ }^{1} \mathrm{H}$ NMR monitoring of the transition in the first cycle. Red and blue solid circles indicate the signals for $\mathbf{1}_{6}$ and $\mathbf{2}_{6}$, respectively. The temperatures at which the measurements were carried out are indicated in the spectra

perfectly blocked by the encapsulation of PCCP in both of the nanocubes (Supplementary Fig. 12). Surprisingly, the addition of 2 eq of PCCP in a 1:1 mixture of $\mathbf{1}_{6}$ and $\mathbf{2}_{6}$ accelerated the scrambling (the scrambling finished in 1 day, which is faster than that carried out in the absence of PCCP (2 days)) (Supplementary Fig. 13). Right after the addition of PCCP in a solution of $\mathbf{1}_{6}$ and $\mathbf{2}_{6}$, all PCCP molecules were selectively encapsulated in thermally less stable $\mathbf{2}_{6}$ under kinetic control. Then the exchange of PCCP between the nanocubes coincided with the scrambling of GSAs between the nanocubes. A simple mixing of $\mathbf{1}_{6}$ and $\mathrm{PCCP}_{2} @ \mathbf{2}_{6}$ also accelerated the scrambling (1 day) (Supplementary Fig. 14). The acceleration of the scrambling under this condition is ascribed to the dissociation of monomer 1 initiated by the transfer of PCCP encapsulated in $\mathbf{2}_{6}$ into $\mathbf{1}_{6}\left(\mathrm{PCCP}_{2} @ \mathbf{2}_{6}+\mathbf{1}_{6} \rightarrow \mathrm{PCCP}_{2} @ \mathbf{1}_{6}+\mathbf{2}_{6}\right)$.

Because of the lower stability of the ordered state at $25^{\circ} \mathrm{C}$, spontaneous scrambling takes place to reach the disordered state. To control the timing of the scrambling, a guestencapsulation-release system was coupled with the cycle of transitions (Fig. 4c and Supplementary Fig. 15). After the formation of a mixture of homoleptic nanocubes from the disordered state, a hydrophobic guest molecule (Hex: $n$-hexane) was added in the mixture to form the nanocubes that encapsulate the guest molecules, Hex $3 @ \mathbf{1}_{6}$ and Hex ${ }_{2} @ 2_{6}$. The scrambling of the GSAs between the two nanocubes was blocked for 7 days, indicating that the metastable ordered state was kinetically locked. The removal of the guest molecules by heating at $100^{\circ}$ $\mathrm{C}$ is the trigger to unlock the ordered state to lead to a mixture of guest-free homoleptic nanocubes, $\mathbf{1}_{6}$ and $\mathbf{2}_{6}$, which then was converted into the disordered state again.

\section{Discussion}

In conclusion, a temperature-controlled cycle of transitions that is fabricated from two kinds of building blocks that self-assemble into homoleptic and heteroleptic cubic assemblies (nanocubes) with different thermal stability was realized. The scrambling experiments (intermolecular exchange) of the building blocks (GSAs) between the nanocubes indicate that the kinetic stability of the nanocube is closely related to the thermal stability of the nanocubes; a thermally more stable nanocube is kinetically more inert. The concentration effect on the rate of the scrambling and the results obtained from the scrambling experiments in the presence of guest molecules indicate that the scrambling takes place through the exchange of free GSAs dissociated from the nanocubes and that the rate of the scrambling is determined by the dissociation of free GSAs provided from a thermally more stable nanocube. The interconversion between the metastable 


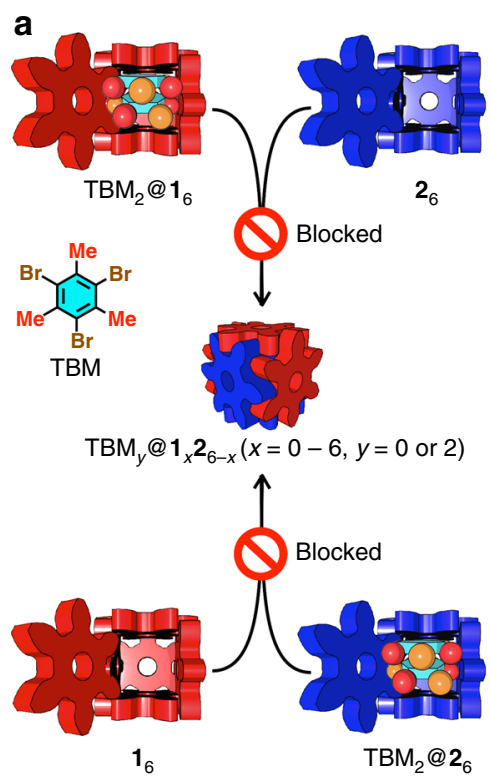

C

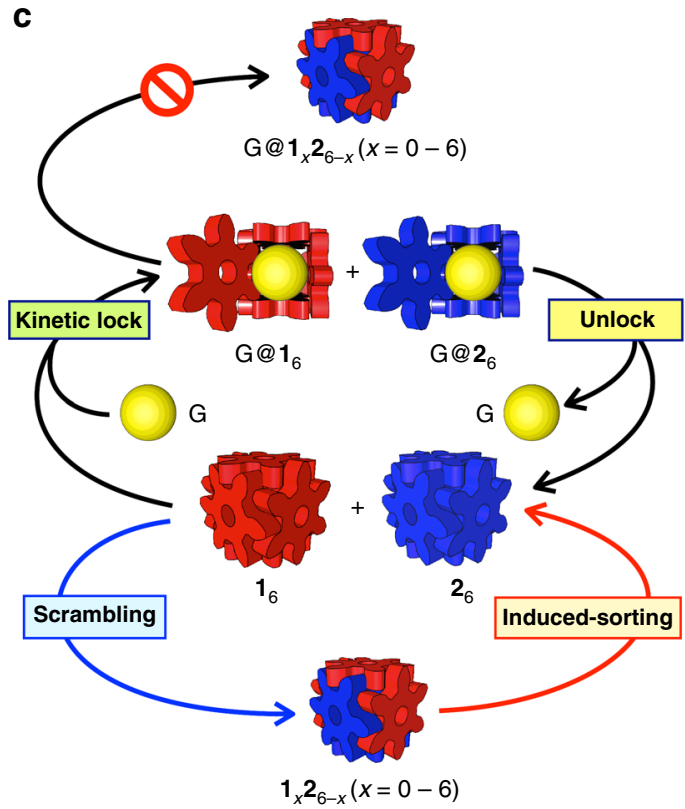

b
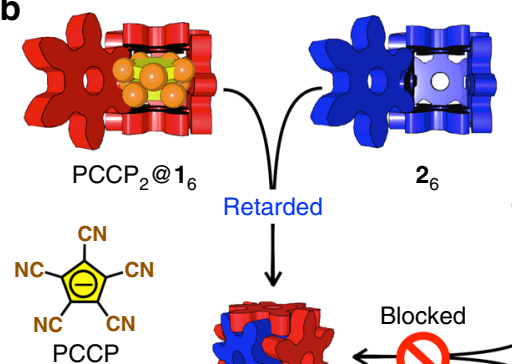

$\downarrow$

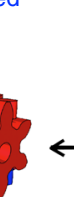

$\mathrm{PCCP}_{y} @ \mathbf{1}_{x} \mathbf{2}_{6-x}(x=0-6, y=0$ or 2$)$
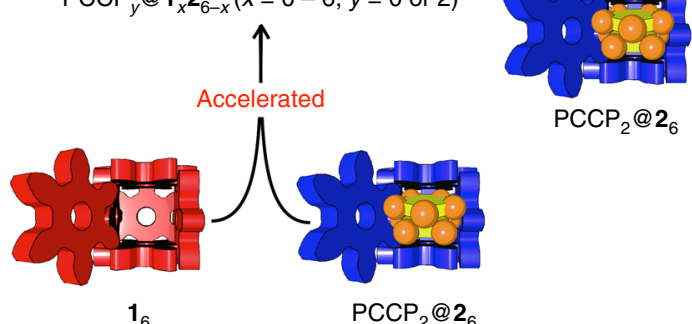

$1_{6}$

d

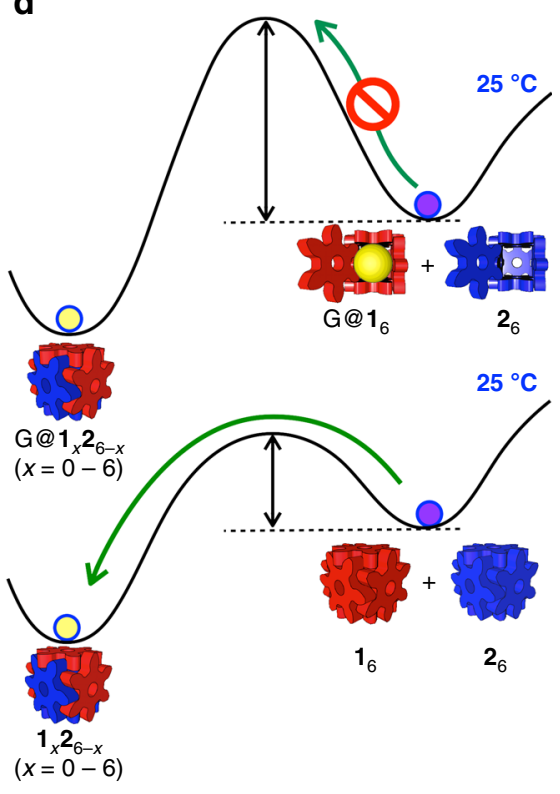

Fig. 4 The effect of guest molecules on the scrambling of GSAs between the nanocubes $\left(\mathbf{1}_{6}\right.$ and $\left.\mathbf{2}_{6}\right)$. a The encapsulation of hydrophobic guest molecules (TBM: 1,3,5-tribromomesitylene) in $\mathbf{1}_{6}$ or $\mathbf{2}_{6}$ blocked the scrambling. b Anionic guest molecule (PCCP: pentacyanocyclopentadienide) accelerated, retarded, and blocked the scrambling depending on the way of the encapsulation of PCCP in the nanocubes. $\mathbf{c}$ A cycle of the transition between the ordered and disordered states coupled with the kinetic lock and unlock of the ordered state by the encapsulation and release of guest molecules ( $G$ ) in the nanocubes. $G$ indicates two or three molecules of $n$-hexanes. Three molecules of $n$-hexanes are encapsulated in $\mathbf{1}_{6}$, while two in $\mathbf{2}_{6}$. The removal of $\mathrm{G}$ from the nanocubes was carried out by heating at $100^{\circ} \mathrm{C}$. $\mathbf{d ~ A}$ schematic representation of change in the energy landscape of the scrambling of GSAs with hydrophobic guest molecules (G). A mixture of $\mathrm{G} @ \mathbf{1}_{6}$ and $\mathbf{2}_{6}$ is kinetically stable at $25^{\circ} \mathrm{C}(\mathbf{a})$ because the encapsulated hydrophobic guest molecules stabilize the nanocube, giving rise to high activation energy of the scrambling. The same effect works in the cases where the scrambling starts from a mixture of $\mathbf{1}_{6}$ and $\mathrm{G} @ \mathbf{2}_{6}$ (a) and from a mixture of $\mathrm{G} @ \mathbf{1}_{6}$ and $\mathrm{G} @ \mathbf{2}_{6}(\mathbf{c})$

ordered (a mixture of $\mathbf{1}_{6}$ and $\mathbf{2}_{6}$ ) and the thermodynamically most stable disordered states (an almost statistical mixture of $\mathbf{1}_{x} \mathbf{2}_{6-x}(x$ $=0-6)$ ) was realized simply by changing the temperature. The result that the induced-sorted state was preferred by heating at $100^{\circ} \mathrm{C}$ and subsequent rapid cooling was realized because only the nanocubes composed of more 1 can survive at this temperature. The rate of the scrambling can be controlled by anionic guest species. The blocking of the scrambling by the encapsulation of guest molecules would enable to kinetically capture a certain metastable species that is selected from a dynamic combinatorial library of compositional and positional isomers of nanocubes consisting of several kinds of GSAs in response to external stimuli.

\section{Methods}

General. ${ }^{1} \mathrm{H}$ and ${ }^{13} \mathrm{C}$ NMR spectra were recorded using a Bruker AV-500 (500 $\mathrm{MHz}$ ) spectrometer. High-resolution mass spectra (HRMS) were obtained using a Waters Xevo G2-S QTOF mass spectrometer. All reagents were obtained from commercial suppliers (TCI Co., Ltd., WAKO Pure Chemical Industries Ltd., KANTO Chemical Co., Inc., and Sigma-Aldrich Co.) and were used as received. GSAs $\mathbf{1} \cdot \mathrm{Cl}_{2}$ and $2 \cdot \mathrm{Cl}_{2}$ and compounds $\mathbf{3}$ and $\mathbf{4}$ were synthesized according to 
previously reported procedures ${ }^{35}$. See supplementary information for synthetic procedures, including Supplementary Figs. 16-19.

Host-guest complexation. The solutions of $\mathrm{TBM}_{2} @ \mathbf{1}_{6}, \mathrm{TBM}_{2} @ \mathbf{2}_{6}$ (TBM indicates 1,3,5-tribromomesitylene), PCCP ${ }_{2} @ \mathbf{1}_{6}$ (PCCP indicates pentacyanocyclopentadienide) and $\mathrm{Hex}_{3} @ \mathbf{1}_{6}$ (Hex indicates $n$-hexane) were prepared according to the literatures ${ }^{35,37}$. Hex $(1 \mu \mathrm{L})$ was added by a syringe to a $\mathrm{D}_{2} \mathrm{O}$ solution of $\mathbf{2}_{6}([2]=$ $1.0 \mathrm{mM}, 600 \mu \mathrm{L})$ in an NMR tube. The suspension was mixed by inverting the NMR tube four times and sonicated for 5 min to afford $\mathrm{Hex}_{2} @ \mathbf{2}_{6}$ (Supplementary Fig. 1). The formation of $\mathrm{PCCP}_{2} @ 2_{6}$ was confirmed by the titration experiments using the ${ }^{1} \mathrm{H}$ NMR signals of the nanocube encapsulating PCCPs (Supplementary Fig. 2).

\section{Monitoring of scrambling by ESI-TOF mass spectrometry. ESI-TOF mass} spectra of the scrambling of the nanocubes in water were recorded on a SYNAPT G2-Si HDMS mass spectrometer (Waters, Massachusetts, Milford, USA) in negative ionization mode at $0.88 \mathrm{kV}$ with a $0 \mathrm{~V}$ sampling cone voltage and source offset voltage, $4 \mathrm{~V}$ trap and $2 \mathrm{~V}$ transfer collision energy, and $1.5 \mathrm{~mL} / \mathrm{min}$ trap gas flow. The scrambling experiment between $\mathbf{1}_{6}$ and $\mathbf{1 D}_{6}$ was presented as an example. Solutions of $\mathbf{1}_{6}$ and of $\mathbf{1 D}_{6}([\mathrm{GSA}]=0.8 \mathrm{mM})$ in $\mathrm{H}_{2} \mathrm{O}$ were prepared separately. The solutions of $\mathbf{1}_{6}(150 \mu \mathrm{L})$ and of $1 \mathbf{D}_{6}(150 \mu \mathrm{L})$ were added to an Eppendorf microcentrifuge tube. Then, the concentration of GSAs was adjusted to be $0.4,0.1$, and $0.025 \mathrm{mM}$ by addition of Milli-Q water. The scrambling of the GSAs was monitored by mass spectrometry. A portion of the mixture was taken. After addition of $1 \mathrm{mM} \mathrm{H}_{2} \mathrm{SO}_{4}$ aq., this solution was immediately injected into goldcoated glass capillaries made in house ( $\sim 5 \mathrm{~L}$ sample loaded per analysis) and the mass spectrum was recorded. The spectra were calibrated using $1 \mathrm{mg} / \mathrm{mL}$ CsI and analyzed using MassLynx software (Waters).

Monitoring of scrambling by ${ }^{\mathbf{1}} \mathbf{H}$ NMR spectroscopy. Solutions of $\mathbf{1}_{6}$ and of $\mathbf{2}_{6}$ $([\mathrm{GSA}]=2 \mathrm{mM})$ in $\mathrm{D}_{2} \mathrm{O}$ were prepared separately. A solution of TMACl $(8 \mathrm{mM}$, TMACl indicates tetramethylammonium chloride) in $\mathrm{D}_{2} \mathrm{O}(15 \mu \mathrm{L})$, which was used as an internal standard, was added to an Eppendorf microcentrifuge tube. Then the solutions of $\mathbf{1}_{6}(120 \mu \mathrm{L})$ and of $\boldsymbol{2}_{6}(120 \mu \mathrm{L})$ in $\mathrm{D}_{2} \mathrm{O}$ and $\mathrm{D}_{2} \mathrm{O}(345 \mu \mathrm{L})$ were added to the Eppendorf microcentrifuge tube to adjust the concentration of GSAs to $0.4 \mathrm{mM}$ or the solutions of $\mathbf{1}_{6}(150 \mu \mathrm{L})$ and of $\mathbf{2}_{6}(150 \mu \mathrm{L})$ in $\mathrm{D}_{2} \mathrm{O}$ and $\mathrm{D}_{2} \mathrm{O}(285 \mu \mathrm{L})$ were added to the Eppendorf microcentrifuge tube to adjust the concentration of GSAs to $0.5 \mathrm{mM}$. The scrambling of the GSAs was monitored at $25^{\circ} \mathrm{C}$ by ${ }^{1} \mathrm{H}$ NMR spectroscopy. The existence ratios of $\mathbf{1}_{6}$ and $\mathbf{2}_{6}$ were determined by their integrated values against that of the signal of $\mathrm{TMA}^{+}$. Three $p$-tolyl methyl signals observed at $0.5-2 \mathrm{ppm}$ were used to determine the existence ratio of $\mathbf{1}_{6}$. As $\mathbf{2}_{6}$ lacks $p$-tolyl methyl groups, $N$-methyl signals at 3-4 ppm were used to determine the existence ratio of $\mathbf{2}_{6}$. In order to confirm the reproducibility of the measurements, the same experiments were carried out three times. Similar procedures were conducted for the scrambling of the nanocubes with guest molecules. See supplementary information for more details (Supplementary Figs. 3, 4 and 7-14).

\section{Interconversion between ordered and disordered states in a mixture of}

nanocubes. An almost statistical mixture of the nanocubes $\mathbf{1}_{x} \mathbf{2}_{6-x}(x=0-6)$ was produced from a mixture of $\mathbf{1}_{6}$ and $\mathbf{2}_{6}([\mathbf{1}]=[\mathbf{2}]=0.5 \mathrm{mM})$ at $25^{\circ} \mathrm{C}$ for 3 days or at $50^{\circ} \mathrm{C}$ for $8 \mathrm{~h}$. A mixture of $\mathbf{1}_{6}$ and $\mathbf{2}_{6}$ was preferentially produced by heating at $100^{\circ} \mathrm{C}$ for $20 \mathrm{~min}$ followed by rapid cooling at $0^{\circ} \mathrm{C}$ for $20 \mathrm{~s}$. The induced-sorting of $\mathbf{1}_{6}$ and $\mathbf{2}_{6}$ was monitored by variable temperature ${ }^{1} \mathrm{H}$ NMR measurements (Supplementary Figs. 5 and 6 ).

Kinetic lock and unlock of the induced-sorted state by the encapsulation and release of guest molecules. $n$-Hexane (Hex) $(1 \mu \mathrm{L})$ was added via a syringe to a $\mathrm{D}_{2} \mathrm{O}$ solution of $\mathbf{1}_{6}$ and $\mathbf{2}_{6}([\mathbf{1}]=[\mathbf{2}]=0.5 \mathrm{mM})$ in an NMR tube. The suspension was mixed by shaking the NMR tube for $30 \mathrm{~s}$ to afford a $\mathrm{D}_{2} \mathrm{O}$ solution of $\mathrm{Hex}_{3} @ \mathbf{1}_{6}$ and $\mathrm{Hex}_{2} @ \mathbf{2}_{6}$. The encapsulated $n$-hexane was removed upon heating at $100^{\circ} \mathrm{C}$ for $60 \mathrm{~min}$ and then a mixture of $\mathbf{1}_{6}$ and $\mathbf{2}_{6}$ was obtained by rapid cooling at $0^{\circ} \mathrm{C}$ for 20 s (Supplementary Fig. 15).

\section{Data availability}

The authors declare that all the other data supporting the findings of this study are available within the article and its supplementary information files and from the corresponding author upon request.

Received: 22 October 2018 Accepted: 12 March 2019

Published online: 29 March 2019

\section{References}

1. Yang, R. Gas Separation by Adsorption Processes. (Elsevier Science, Kent, 2014).

2. Bernardo, P., Drioli, E. \& Golemme, G. Membrane gas separation: a review/ state of the art. Ind. Eng. Chem. Res. 48, 4638-4663 (2009).
3. Leff, H. \& Rex, A. F. Maxwell's Demon: Entropy, Information, Computing. (Adam Hilger, Bristol, 1990).

4. Leff, H. \& Rex, A. F. Maxwell's Demon 2: Entropy, Classical and Quantum Information, Computing (CRC Press, Boca Raton, 2002).

5. Liu, M., Zhang, L. \& Wang, T. Supramolecular chirality in self-assembled systems. Chem. Rev. 115, 7304-7397 (2015).

6. Jẹdrzejewska, H. \& Szumna, A. Making a right or left choice: chiral self-sorting as a tool for the formation of discrete complex structures. Chem. Rev. 117, 4863-4899 (2017)

7. Pritchard, V. E. et al. Homochiral self-sorted and emissive Ir ${ }^{\mathrm{III}}$ metallocryptophanes. Chem. Eur. J. 23, 6290-6294 (2017).

8. Safont-Sempere, M. M. et al. Impact of molecular flexibility on binding strength and self-sorting of chiral $\pi$-surfaces. J. Am. Chem. Soc. 133, 9580-9591 (2011).

9. Makiguchi, W. et al. Chirality- and sequence-selective successive self-sorting via specific homo- and complementary-duplex formations. Nat. Commun. 6 , $7236(2015)$

10. Safont-Sempere, M. M., Fernández, G. \& Würthner, F. Self-sorting phenomena in complex supramolecular systems. Chem. Rev. 111, 5784-5814 (2011).

11. Petryk, M., Biniek, K., Janiak, A. \& Kwit, M. Unexpected narcissistic selfsorting at molecular and supramolecular levels in racemic chiral calixsalens. CrystEngComm 18, 4996-5003 (2016).

12. Sisco, S. W. \& Moore, J. S. Homochiral self-sorting of BINOL macrocycles. Chem. Sci. 5, 81-85 (2014).

13. Gidron, O. et al. Homochiral [2]catenane and bis[2]catenane from allenoacetylenic helicates-a highly selective narcissistic self-sorting process. J. Am. Chem. Soc. 137, 12502-12505 (2015).

14. Prins, L. J., De Jong, F., Timmerman, P. \& Reinhoudt, D. N. An enantiomerically pure hydrogen-bonded assembly. Nature 408, 181-184 (2000).

15. Yan, L.-L. et al. Stereocontrolled self-assembly and self-sorting of luminescent europium tetrahedral cages. J. Am. Chem. Soc. 137, 8550-8555 (2015).

16. Ronson, T. K., Roberts, D. A., Black, S. P. \& Nitschke, J. R. Stacking interactions drive selective self-assembly and self-sorting of pyrene-based $\mathrm{M}^{\mathrm{II}}{ }_{4} \mathrm{~L}_{6}$ architectures. J. Am. Chem. Soc. 137, 14502-14512 (2015).

17. Zheng, Q. et al. Self-sorting of heteroanions in the assembly of crossshaped polyoxometalate clusters. J. Am. Chem. Soc. 140, 2595-2601 (2018).

18. Wang, X. et al. Assembled molecular face-rotating polyhedra to transfer chirality from two to three dimensions. Nat. Commun. 7, 12469 (2016).

19. Shigemitsu, H. et al. An adaptive supramolecular hydrogel comprising selfsorting double nanofibre networks. Nat. Nanotech. 13, 165-172 (2018).

20. Lehn, J.-M. Perspectives in chemistry-steps towards complex matter. Angew. Chem. Int. Ed. 52, 2836-2850 (2013).

21. Lehn, J.-M. Perspectives in chemistry-aspects of adaptive chemistry and materials. Angew. Chem. Int. Ed. 54, 3276-3289 (2015).

22. Herder, M. \& Lehn, J.-M. The photodynamic covalent bond: sensitized alkoxyamines as a tool to shift reaction networks out-of-equilibrium using light energy. J. Am. Chem. Soc. 140, 7647-7657 (2018).

23. Boekhoven, J., Hendriksen, W. E., Koper, G. J. M., Eelkema, R. \& van Esch, J. H. Transient assembly of active materials fueled by a chemical reaction. Science 349, 1075-1079 (2015).

24. Sorrenti, A., Leira-Iglesias, J., Markvoort, A. J., de Greef, T. F. A. \& Hermans, T. M. Non-equilibrium supramolecular polymerization. Chem. Soc. Rev. 46, 5476-5490 (2017)

25. Osowska, K. \& Miljanić, O. Š. Oxidative kinetic self-sorting of a dynamic imine library. J. Am. Chem. Soc. 133, 724-727 (2011).

26. Vantomme, G., Jiang, S. \& Lehn, J.-M. Adaptation in constitutional dynamic libraries and networks, switching between orthogonal metalloselection and photoselection processes. J. Am. Chem. Soc. 136, 9509-9518 (2014).

27. Zhou, Z., Yue, L., Wang, S., Lehn, J.-M. \& Willner, I. DNA-based multiconstituent dynamic networks: hierarchical adaptive control over the composition and cooperative catalytic functions of the systems. J. Am. Chem. Soc. 140, 12077-12089 (2018)

28. Ragazzon, G. \& Prins, L. J. Energy consumption in chemical fuel-driven self-assembly. Nat. Nanotech. 13, 882-889 (2018).

29. van Rossum, S. A. P., Tena-Solsona, M., van Esch, J. H., Eelkema, R. \& Boekhoven, J. Dissipative out-of-equilibrium assembly of man-made supramolecular materials. Chem. Soc. Rev. 46, 5519-5535 (2017).

30. Merindol, R. \& Walther, A. Materials learning from life: concepts for active, adaptive and autonomous molecular systems. Chem. Soc. Rev. 46, 5588-5619 (2017).

31. Zhao, H. et al. Reversible trapping and reaction acceleration within dynamically self-assembling nanoflasks. Nat. Nanotech. 11, 82-88 (2016).

32. Kathan, M. \& Hecht, S. Photoswitchable molecules as key ingredients to drive systems away from the global thermodynamic minimum. Chem. Soc. Rev. 46, 5536-5550 (2017).

33. Hess, H. \& Ross, J. L. Nonequilibrium assembly of microtubules: from molecules to autonomous chemical robots. Chem. Soc. Rev. 46, 5570-5587 (2017).

34. Tena-Solsona, M., Wanzke, C., Riess, B., Bausch, A. R. \& Boekhoven, J. Selfselection of dissipative assemblies driven by primitive chemical reaction networks. Nat. Commun. 9, 2044 (2018). 
35. Zhan, Y.-Y. et al. Hyperthermostable cube-shaped assembly in water. Commun. Chem. 1, 14 (2018).

36. Zhan, Y.-Y., Kojima, T., Koide, T., Tachikawa, M. \& Hiraoka, S. A balance between van der Waals and cation- $\pi$ interactions that stabilizes hydrophobic assemblies. Chem. Eur. J. 24, 9130-9135 (2018).

37. Zhan, Y.-Y. et al. Induced-fit expansion and contraction of a self-assembled nanocube finely responding to neutral and anionic guests. Nat. Commun. 9, 4530 (2018).

\section{Acknowledgements}

This research was supported by JSPS Grants-in-Aid for Scientific Research on Innovative Areas "Dynamical Ordering of Biomolecular Systems for Creation of Integrated Functions" (25102001 and 25102005), the Mitsubishi Foundation, Sekisui Integrated Research, and the Joint Research by Exploratory Research Center on Life and Living Systems (ExCELLS).

\section{Author contributions}

Y.-Y.Z., T.K., S.T., and S.H. conceived the project. S.H. prepared the manuscript and all the authors discussed the results and commented on the manuscript. Y.-Y.Z. synthesized all the GSAs and carried out NMR measurements. K.I. and S.U. carried out mass measurements. Y.H. and H.M. synthesized NaPCCP.

\section{Additional information}

Supplementary Information accompanies this paper at https://doi.org/10.1038/s41467019-09495-1.
Competing interests: The authors declare no competing interests.

Reprints and permission information is available online at http://npg.nature.com/ reprintsandpermissions/

Journal peer review information: Nature Communications thanks the anonymous reviewers for their contribution to the peer review of this work. Peer reviewer reports are available.

Publisher's note: Springer Nature remains neutral with regard to jurisdictional claims in published maps and institutional affiliations.

(c) (i) Open Access This article is licensed under a Creative Commons Attribution 4.0 International License, which permits use, sharing, adaptation, distribution and reproduction in any medium or format, as long as you give appropriate credit to the original author(s) and the source, provide a link to the Creative Commons license, and indicate if changes were made. The images or other third party material in this article are included in the article's Creative Commons license, unless indicated otherwise in a credit line to the material. If material is not included in the article's Creative Commons license and your intended use is not permitted by statutory regulation or exceeds the permitted use, you will need to obtain permission directly from the copyright holder. To view a copy of this license, visit http://creativecommons.org/ licenses/by/4.0/.

(C) The Author(s) 2019 